\title{
Why Do Electricity Policy and Competitive Markets Fail to Use Advanced PV Systems to Improve Distribution Power Quality?
}

\author{
Mark P. McHenry, ${ }^{1}$ Jay Johnson, ${ }^{2}$ and Mike Hightower ${ }^{2}$ \\ ${ }^{1}$ School of Veterinary and Life Sciences, Murdoch University, Murdoch, WA 6150, Australia \\ ${ }^{2}$ Sandia National Laboratories, Albuquerque, NM 87185, USA \\ Correspondence should be addressed to Mark P. McHenry; mpmchenry@gmail.com
}

Received 23 March 2016; Revised 23 June 2016; Accepted 27 June 2016

Academic Editor: Paulo Fernandes

Copyright (C) 2016 Mark P. McHenry et al. This is an open access article distributed under the Creative Commons Attribution License, which permits unrestricted use, distribution, and reproduction in any medium, provided the original work is properly cited.

\begin{abstract}
The increasing pressure for network operators to meet distribution network power quality standards with increasing peak loads, renewable energy targets, and advances in automated distributed power electronics and communications is forcing policy-makers to understand new means to distribute costs and benefits within electricity markets. Discussions surrounding how distributed generation (DG) exhibits active voltage regulation and power factor/reactive power control and other power quality capabilities are complicated by uncertainties of baseline local distribution network power quality and to whom and how costs and benefits of improved electricity infrastructure will be allocated. DG providing ancillary services that dynamically respond to the network characteristics could lead to major network improvements. With proper market structures renewable energy systems could greatly improve power quality on distribution systems with nearly no additional cost to the grid operators. Renewable DG does have variability challenges, though this issue can be overcome with energy storage, forecasting, and advanced inverter functionality. This paper presents real data from a large-scale grid-connected PV array with large-scale storage and explores effective mitigation measures for PV system variability. We discuss useful inverter technical knowledge for policy-makers to mitigate ongoing inflation of electricity network tariff components by new DG interconnection requirements or electricity markets which value power quality and control.
\end{abstract}

\section{Introduction}

Globally, there are comparable needs to find cost-effective means to maintain electricity network integrity with increasing peak electricity demand growth and high penetrations of new clean energy systems [1-6]. As a general response to peak demand, electricity sector reforms towards competitive electricity market structures oversaw large investments in new generation capacity. In many jurisdictions this has arguably disregarded investments in fuel supply diversity and security, and not reinforcing the electricity network or improving the power quality $[2,7]$. In terms of new renewable energy capacity, while solar photovoltaics (PV) are enjoying a large surge in generation capacity, there is a perception that highpenetration PV variability and integration with conventional electricity infrastructure are technically and economically challenging to achieve $[6,8]$. After a long PV technology development phase, there are increasingly large and growing contributions of $\mathrm{PV}$ in localised regions of electricity networks at both the large- and small-scale which may require new approaches to compensate for the larger or aggregated output fluctuations, depending on the existing network [9, 10]. The immediate concern of electricity network utilities is high penetration of localised PV on low voltage feeders that cause voltage increases in intervals of high PV production during low demand. There is also concern that the combination of the inherent variability of high penetration PV and the conventional small-scale PV inverter behaviour can lead to a higher probability of triggering catastrophic system-wide collapse of the electricity network during reestablishment phases instigated by simple localised faults $[8,11,12]$. Small changes in network frequency are commonly used to monitor the relative balance between load and generation, when the network frequency falls below a preprescribed limit (often 
due to an abnormal current/fault) it can trigger a protective frequency cascading load-shedding scheme that sequentially turns off major loads causing localised blackouts to manage the discrepancy. For an example of a representative network, the largest electricity network in Western Australia (the South West Interconnected System, SWIS) automatically sheds load at around a voltage of $48.75 \mathrm{~Hz}$, lower than the nominal $50 \mathrm{~Hz}$, with a normal fluctuation within $0.4 \%$. Most (>80\%) electricity system faults on the SWIS occur in distribution systems; $80 \%$ of these are grounding faults, of which $90 \%$ are instantaneous grounding faults $[3,13]$. These short-term abnormal currents (sometimes large amperages) require rapid-response technologies to maintain supply. The high impedance of many distribution networks (particularly in rural areas) is generally less able to tolerate load and generation imbalances relative to low impedance networks.

There are also challenges for distribution circuits in unfaulted conditions. Photovoltaics systems are current sources and as the PV inverter injects current into the feeder, due to the impedance of the line, the local voltage will increase. Since voltage regulation is primarily handled at the substation, branch feeders will experience a wide range of voltages depending on the presence of PV systems. As such, it is challenging to maintain voltages in the required range. For example, using a perunit voltage comparison, the high impedance of Australian rural grid (which is generally known as "weak") can be represented by 0.2 per unit (p.u.) relative to a strong grid near an urban substation that can be represented by 0.01 p.u. [8]. It is within this natural variability of the existing networks that proponents/owners of grid-connected PV systems are increasingly becoming entangled within government and network utility discussions concerned with growing penetrations on the diversity of local distribution networks and the associated challenge to meet strict power quality control standards [14]. Furthermore, it is common for long distribution network feeders at the substation to operate very close to the maximum rated voltage allowed by standards and well above nominal voltages to compensate for lower voltages at the end of the feeder remaining within range during high demand times. However, inverter operating voltage ranges are generally set by standards organizations, for example, IEEE 1547 in the US (generally for safety measures), which shut down the inverter if the network voltage is outside the imposed inverter operating range. This also renders them unavailable for network support [8]. These practices, apart from general conservatism, were based on older generation inverters tending to sharply increase current output when the network system voltage dropped suddenly for a fraction of a second due to a network fault, often with the inverter shutting itself down [14]. Predictably, these prescribed preset requirements also may significantly influence the capacity factor of some PV systems depending on how close the PV system is located to the substations with higher than nominal voltages, variable loads, and fault characteristics at the time.

As a consequence, there are periodic calls for standards for small-scale grid-connected renewable energy systems to be revised (e.g., AS/ANZ 4777 in Australia and New Zealand) to require/allow the growing technical capability of PV inverters to actively regulate voltage with power factor/reactive power control akin to the existing standards of large generators. Counterintuitively, while many new smaller PV system inverters are able to absorb or inject reactive power to dynamically compensate for voltage deviations on local feeders (using phase shifting), it is common for the power factors of inverters to be required to be at unity by network operators. This requires the network to support both the normal vagaries of the network, the load, and the inherent PV array volatility, while the advanced inverter functions remain unutilised (medium-to-large PV inverter systems are increasingly being required to provide reactive power control in some jurisdictions.) [11, 12, 15]. It is also uncommon to utilise low voltage ride through (LVRT) capabilities. LVRT is a new requirement in many European and America jurisdictions with the PV inverter remaining connected to the grid for a specified fault duration. Previous grid interconnection requirements stated only that the inverter must disconnect at a certain time. Another capability, defined in the International Electrotechnical Committee (IEC) Technical Report 61850-90-7 [16], is known as Volt-Var. The Volt-Var function requires that the inverter locally measures the grid voltage and autonomously provided reactive power ("Vars" or voltampere reactive power) when there are voltage deviations from nominal. Their ability to provide reactive power to support network will assist with the distribution circuit voltage ranges and could help voltage recovery from faults [14].

This research discusses some recent technical developments that are relevant to policy-makers and offer three views: (1) advancements of large-to-small-scale inverter technical capabilities for automated inverter power quality control support (if enabled) are largely making power quality arguments for preventing additional PV capacity out-of-date; (2) existing large-scale PV inverter systems and relatively small supercapacitor banks working in parallel can moderate rapid network changes that conventional technologies are technically unable to cater for, and (3) existing market mechanisms and regulation approaches largely exclude the existing and rapidly advancing PV/inverter/support system technical capability to automate and improve the existing electricity network that is increasingly available to network operators, particularly the distribution network where network operators traditionally have little ability or capacity to control. As the evolution of electricity policy and pricing mechanisms continue to fall well behind the technical advancements and options available to the network, there are increasing misallocations of resources that do not incentivise/compensate investments in higher efficiency technology that improve dynamic power quality and maximise the existing capacity of distribution networks to meet the growing diversity of new loads within regulated standards of power quality.

\section{Large PV System Ramping Quantified}

Research by Johnson et al. [12] analysed maximum PV ramp rates for December 8, 2010, at various intervals of 1 second, 10 seconds, 1 minute, and 10 minutes for the La Ola 1.2 MW PV array in Lanai, Hawaii, finding $49 \mathrm{~kW}, 194 \mathrm{~kW}, 376 \mathrm{~kW}$, and 
$454 \mathrm{~kW}$ ramp rates, respectively. The system consisted of 12 independently tracking SunPower PV arrays each connected to a SatCon inverter passing through $15 \mathrm{kV}$ switchgear. The 1.2 MW La Ola PV plant was commissioned in 2009 and operates on a small island network with a peak load of $5 \mathrm{MW}$ supplied by eight nearby diesel generators at the Miko station (two 2.2 MW and six 1 MW units). Prior to the PV system interconnection, simulation studies suggested that the full 1.2 MW penetration of the plant would negatively impact network frequency due to PV production volatility reducing the network frequency to a point where a frequency cascading load-shedding scheme sequentially turned off major loads and therefore limited the array to only $50 \%$ of nameplate output as a consequence [12]. Johnson et al. [12] analysed a highly variable day (4 November 2010) to assess the impact of the high penetration PV system on the system voltage. The analysis found a slight temporary effect on voltage during sustained ramps in the morning (in increased voltage) and evening (a decreased voltage) but was well within normal voltage short-term and diurnal variations due to voltage regulation equipment on the island [12]. The research determined that assumption that unmitigated high rampdown rates of high penetration PV will sharply drop network frequency over and above conventional operation was a false assumption for the 1.2 MW La Ola system operating at $600 \mathrm{~kW}$ (around 10\% overall network penetration), even in high irradiance and PV output multiple minute interval ramp rates greater than $200 \mathrm{~kW}$ due to partly cloudy conditions on November 4, 2010 [12]. In 2011 an energy storage system (nominal output of $1.125 \mathrm{MW}$ with $500 \mathrm{kWh}$ storage capacity) was incorporated into the $1.2 \mathrm{MW} \mathrm{La}$ Ola system with the intention of mitigating the high PV ramp rates (limiting them to $360 \mathrm{~kW} \mathrm{~min}^{-1}$ ) and enables the PV system to operate at full rated output of 1.2 MW [12]. To date this new upgraded system has performed well and has not been analysed in detail.

Another selected example is a large PV array in Albuquerque, New Mexico, a battery and supercapacitor system capacity equal to the PV array capacity (while it is an excellent grid-connected research facility doing innovative research, a commercial system would not be cost-effectively designed to match the capacities of storage to capture the entire output of the PV generation component; it is an unnecessary expense and would be regarded as a large storage component over sizing), known as the "PMN Prosperity PV Storage Project." The PMN Prosperity PV Storage Project was commissioned in September 2011 and is operated by the Public Service Company of New Mexico (PNM). The system is currently exploring PV power output smoothing and peak shifting on both end-of-(distribution)feeder and beginningof-(distribution)feeder $(12.47 \mathrm{kV})$ configurations to achieve a minimum of $15 \% \mathrm{PV}$ penetration and storage [17]. The PV system is $0.496 \mathrm{MW}$ PV array $(2,158$ Schott nominal $230 \mathrm{~W}$ and $30 \mathrm{~V}$ panels, with total system output of $390 \mathrm{VDC}$ and $1272 \mathrm{~A}$ ) with a nominal $0.5 \mathrm{MW}$ supercapacitor bank (320 cells in series) for ramp rate smoothing and a nominal $0.25 \mathrm{MW}$ battery bank (advanced carbon lead-acid batteries of 3 strings of 320 cells connected in series) with $0.99 \mathrm{MWh}$ storage for peak load shifting, providing grid-connection

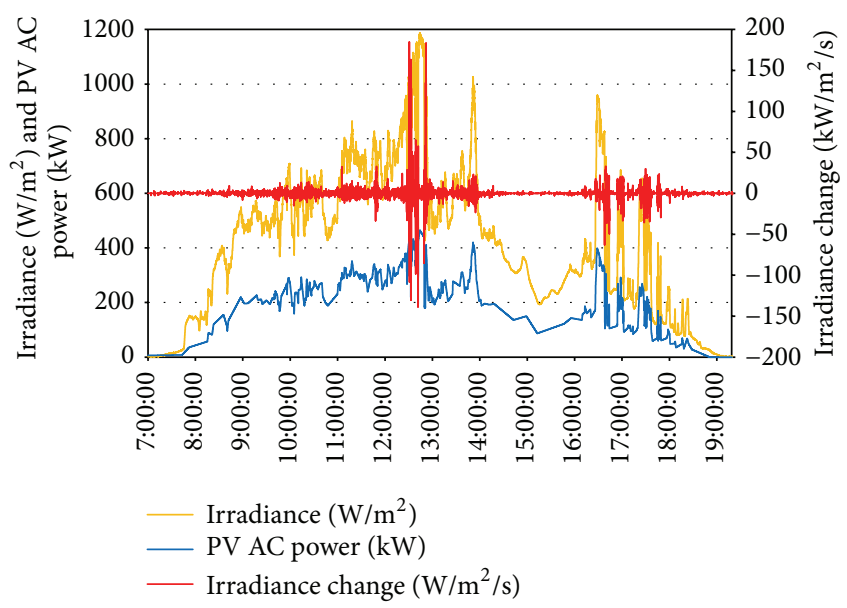

FIGURE 1: A selected day exhibiting extreme solar irradiance variability (yellow) from the PNM Prosperity system showing second interval irradiance volatility (red) and corresponding PV output (blue).

through a nominal $0.75 \mathrm{MW}$ power conditioning system. Crucially, the data acquisition and control system generate 1second resolution data for 220 elements of the system (wind speed, wind direction, temperature, individual PV string monitoring, battery systems, power conditioning, utility feeders, and secure remote connection). System signal speeds between the PV meter and reading by the battery controller were measured at $37 \mathrm{~ms}$, and only 0-2 ms for signals between the average of the five field irradiance sensors evenly spaced around the array at each corner and the middle [18]. The PNM research by Willard et al. [18] showed that data from the PV meter was more effective as a control signal compared to data from irradiance sensors. Figures 1 and 2 show 1 -second data comparing the volatility of the irradiance and the PV output, respectively, all without any storage component or advanced inverter application. The PV array output shows electricity produced postinverter and was remarkably apt at attenuating the rapid fluctuations in the irradiance. However, even with this large attenuation, the raw data from late 2011 and the first half of 2012 showed a maximum PV ramp rate of $\pm 136 \mathrm{~kW} \mathrm{~s}^{-1}$ for the $500 \mathrm{~kW}$ PMN PV array just before 13:00.00 (Figure 2). This was the largest single fluctuation over the months and is presented here due to the extremely volatile conditions on the day. However, while a PV ramp rate of $\pm 136 \mathrm{~kW} \mathrm{~s}^{-1}$ for the $500 \mathrm{~kW}$ PMN PV array may sound like a very large issue, it is important to decouple the discussion at this point to focus on the difference between power (kW) and energy (kWh). Figure 3 shows a 15-minute interval of the rapidly attenuating PV output on the same day. One can view a small section of the red line as a polynomial function; the integral of the PV output (the blue line) is the change in PV output (the red line). Importantly, energy storage is what is needed to "fill in" the reduction of PV output in the blue line to provide a consistent PV system output and is relatively inconsequential. For example, the extreme drop in PV output of $200 \mathrm{~kW}$ in 12:41.46 from $400 \mathrm{~kW}$ to $200 \mathrm{~kW}$ over an approximate interval of 30 seconds corresponds to 


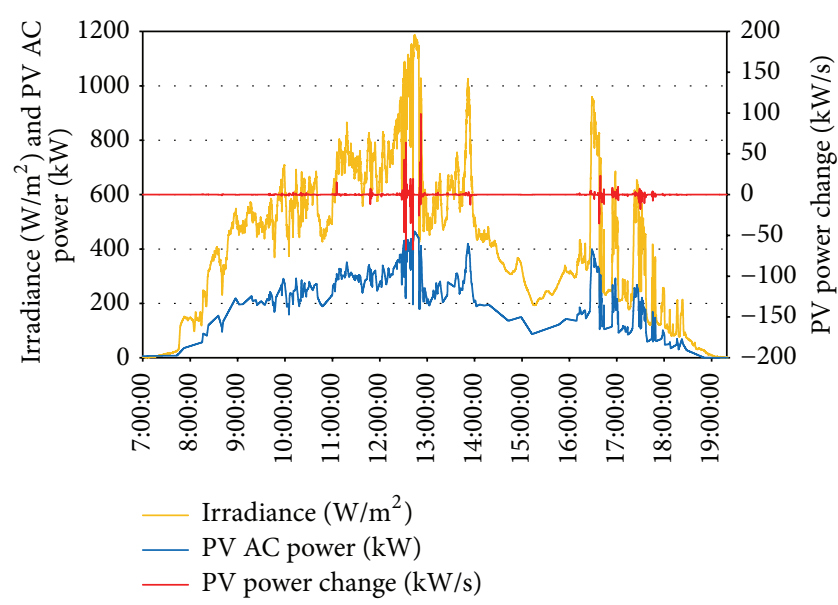

FIgURE 2: The same day exhibiting extreme solar irradiance variability (yellow) and PV output (blue), with the PNM Prosperity system output relatively lower volatility shown in red.

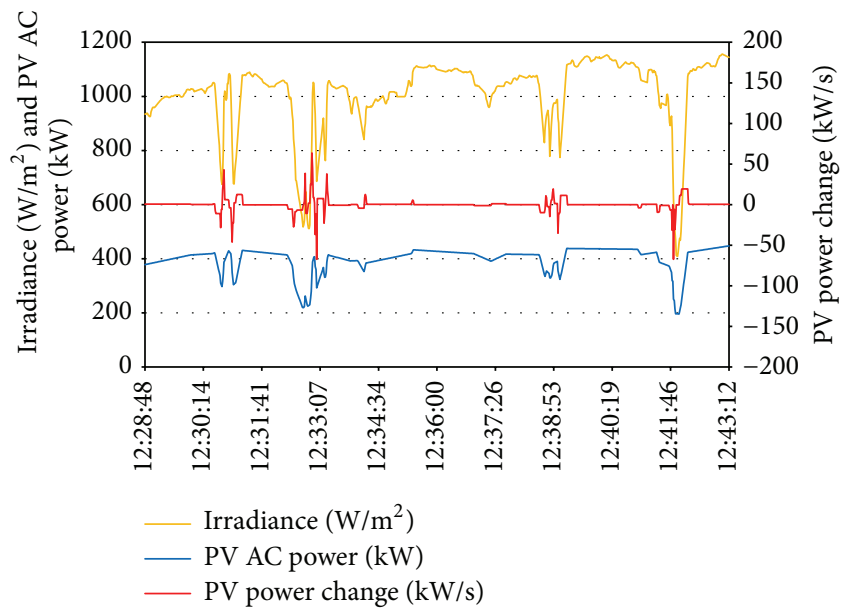

FIgURE 3: Selected zoom view of data shown in Figure 2 indicating higher resolution irradiance as compared to the PV output and PV output volatility, showing the attenuation of the fluctuating solar resource in terms of the PV produced by the system.

a total "energy" required to maintain the $400 \mathrm{~kW}$ of only around $1.6 \mathrm{kWh}$, a relatively tiny amount of energy. However, providing $200 \mathrm{~kW}$ of power was conventionally challenging until new electronically enabled devices now enable the ability to decouple "power" and "energy" elements. Hybrid battery-based energy storage systems are extraordinarily fast, and many can ramp up to full output capacity in less than a second. This is exactly the premise behind the PNM system incorporating a nominal $500 \mathrm{~kW}$ supercapacitor bank for ramp rate smoothing and a nominal $990 \mathrm{kWh}$ battery storage component for peak load shifting. While the inherent rapid fluctuations are often touted as a "fatal flaw" of PV systems, there are numerous means presently available (and many more in development) to reduce and indeed improve the net impact of PV on the electricity network that policy-makers would do well to be aware of.

\section{The "Status" Quo of PV on Electricity Networks}

3.1. What Is the Variability of PV and Impact on Distribution Network? In contrast to the widely discussed speculation of potential impacts, high PV penetration, and numerous simulation research refining probable impacts, there is surprisingly little published information of actual system data of high penetration solar PV variability and the associated level of impact on the local electricity network and overall power system stability [8]. Nonetheless, the instantaneous management of high penetration renewable output under conditions of variable meteorological conditions is a relatively new challenge for network operators [9]. The balance of advantages and disadvantages of decentralised renewable energy systems requires investigation at the local geographical scale to ensure that efficient investments occur which consider overall present network design and performance, the numerous technology alternatives available, cost minimisation, and resultant emission mitigation [19]. Traditional means of managing distribution network voltage deviations using voltage regulators and load tap changers are not designed to tolerate the rapid ramp rates generated by high penetrations of high variability PV system output [18]. PV system output is proportional to the spatial average plane of array (POA) irradiance over the entire array footprint $[11,12]$, and feeders with high penetration of PV can experience ramp rates from close to zero to full output in seconds [18]. Partially cloudy days produce the short-term rapid variability of PV systems, not diurnal intermittency, cloudless days, or consistently overcast days $[8,18]$. The fast moving, welldefined, randomly shaped cumulus clouds within a clear sky pose the greatest challenge to network operators as it reduces the ability to predict PV output [8]. In practice the PV array outputs act like extremely fast "ramp-up" and "rampdown" of traditional generation (see Figures 1-3) [10]. Partial shading from clouds, foliage, or moving objects can lead to rapid fluctuations in DC output and reduce the output from other fully illuminated cells unless the bypass diodes effectively remove the shaded module from the string [20, 21]. Therefore, PV system configuration is another important factor of system reliability and performance, particularly when shading occurs [21]. Furthermore, successfully achieving high PV network penetration is not simply a technical issue and is dependent to some extent of what is deemed acceptable in terms of power quality, stability, reliability, and scheduling, and both historical conventions and mandated standards for electricity supply systems vary widely around the world [8].

A major generator that rapidly fluctuates is a correspondingly concern when it is in a high network penetration scenario [22], often leading to power quality issues and premature failures of power infrastructure [18]. However, a major advantage for high penetration PV is the advancements in accurate prediction of when PV output will rapidly fluctuate and improved meteorological forecasts can specifically cater for PV systems to counter the generally overconservative estimations from conventional forecasts (down to the level of irradiance intermittency patterns of small time intervals 
and also cloud type) [18]. Higher precision meteorological forecasts enable network operators to have greater confidence in actual PV production (as per the cited La Ola PMN Prosperity data acquisition system), and the associated decreased uncertainty can lead to the procurement of less load following capacity, often at an order of magnitude less conventional capacity to follow the high penetration renewables [8]. However, at this time the ability to effectively dispatch existing compensatory generation to match $\mathrm{PV}$ ramp rates is extremely limited with existing network technologies, and the level of compensation will vary widely over different time intervals and meteorological conditions (both when PV output increases and when PV output decreases) [12]. The use of commonly available system data time intervals of 1 hour is wholly insufficient to analyse both PV output fluctuations and electricity dispatch needs [8]. One-minute system data is essential to reduce rapid ramping of PV arrays using smoothing technologies [18]. However, while 1-minute interval PV ramp rates can be large, the ramp rates of PV systems at 1-second intervals can be extremely volatile [12]. This research proposes that a data resolution of at least 1 second is required to characterise the ramp rate of a $\mathrm{PV}$ system and inform corrective decision-making for technical and policy-related regulation decision-making alike.

\subsection{Conventional Network Control Background and New} Developments. When the electrical load exceeds supply the local network frequency and voltage commonly decrease below nominal and vice versa. Historically, network system frequency and voltage are controlled centrally by real power and reactive power equipment, respectively. Network capacitance produced by capacitive phase shifting or capacitors increase voltage, and inductance produced by inductive phase shifting from coils decreases voltage. Older and small-scale PV inverters once produced only "real power" (measured in Watts), with the current and voltage in phase to maximise power output. In contrast, more modern inverters increasingly have a range of advanced abilities (utilised to varying extents) to moderate fluctuations in both the PV output and also the local network by absorbing or generating reactive power (measured in Volt-Amps-reactive, VAr) (in simple terms, the relationship between active (sometimes called "real") power and reactive power is that their vector sum (also the product of the root-mean-square of voltage and current) is known as "apparent" power, measured in Volt-Amps (VA). The term "power factor" is defined as the ratio between real power measured in Watts $(\mathrm{W})$ and the apparent power: (W/VA). When current and voltage are perfectly in phase the power factor is 1 (known as unity), or when $90^{\circ}$ out of phase it is 0 . Power factors can be improved by the inclusion of network components compared to moderate reactive power on the network and improve power factors (such as capacitors and synchronous motors)) and several other advanced capabilities. These abilities are fundamentally different to traditional centralised/manual methods of voltage control (such as using conventional tap changers located at the distribution branches to increase or decrease the voltage and also parallel capacitor banks along the distribution line between tap changers). While traditional approaches do improve voltage control and capacitors emulate spinning reserve to provide additional VAr, they are known to generate unwanted step-changes in voltage along the distribution line, and the traditional capacitor bank switching creates propagating transients along the line. Such approaches are becoming increasingly outmoded and insufficient compared to many modern components (such as supercapacitors) and their associated new applications, particularly for extreme/emergency situations (e.g., supercapacitor banks, as opposed to conventional capacitor banks, have the ability to absorb and inject both real and reactive power). There are a growing array of technical options to reduce issues associated with network voltage and frequency and also PV intermittency, including storage, improved conventional network infrastructure, load control, greater network ancillary equipment, intermittent generator curtailment, demand side management. Each technical option will influence the cost (positively or negatively) of either energy or quality of energy supply in a different manner due to the existing conditions and variability of the baseline infrastructure $[1,4,8]$. A relatively simple option on distribution networks is the use of automated distributed PV inverters, yet this will require two nontechnical policy-related advances: (1) changes in operational requirements of gridconnected inverters and (2) compensatory measures to justify the additional cost of more advanced inverter technology providing frequency and voltage control ancillary services that cater for network vagaries outside of the influence of the PV array itself. For example, the provision of reactive power by inverters compensates for the additional real power produced by the array when high voltage conditions occur, acting like an additional load on distribution networks to maintain a lower voltage and preventing inverter self-shut down. Without curtailing PV output or the load, automated reactive power production or consumption by the enabled $\mathrm{PV}$ inverter is also able to regulate transient voltage fluctuations on the distribution network in parallel. Further, PV inverters are operating at rated real power only a small fraction of the day. In cases where they are not at their nameplate capacity, reactive power is available "free" because the device will have headroom before reaching its apparent power or current limits. As reactive power can be considered an ancillary service on distributed systems, compensation through tariff network components to PV system owners who provide such services should be established on $\$ \mathrm{kVAr}^{-1}$ basis for the additional cost of the reactive power capability, any inverter oversizing, and the relatively small real power production derating (in cases where the inverter is operating at less than full output, newer small-scale PV inverters are able to reallocate resources from the unused portion of the inverter for providing VAr support without an oversized inverter). The seemingly simple example belies the existence of many challenges of load frequency control (frequency variation (and also voltage) is also an unavoidable consequence of variations in demand, despite rapid increases or decreases in frequency indicate operational capacity limits) on networks with high PV penetration which commonly exhibit high rates of voltage flicker and associated transformer tap changes that increase maintenance regimes [8]. 
PV is not the first renewable energy technology to be constrained by conventional approaches and thinking. The relatively fast growth of large-scale wind farms was the first renewable energy technology to endure conventional approaches to manage power quality which stifle investment in new technical solutions. Using again the WA SWIS network as the example, the minimum frequency control services determined by the network utility (Western Power) were increased from $30 \mathrm{MW}$ up to $50 \mathrm{MW}$ for the year 2009/10 because greater output from large-scale wind farms connected to transmission networks [23]. In the year 2010/11 this was again raised to the present level of $60 \mathrm{MW}$ for subsequent years (at the time of writing, the total wind farm rated capacity was around $400 \mathrm{MW}$ on the SWIS, which had around 5,000 MW of total system capacity, predominantly gas and coal. However, the majority of wind farms are large multi-MW farms connected to the transmission network, a fundamentally different challenge to small-scale distributed PV systems on the network presently supplying a few percent of total SWIS electricity consumption. Nonetheless, a network-wide approach of simply adding more generation to provide minimum frequency control services for transmission lines does little to stimulate greater investment in more targeted technical solutions and also ignores the opportunities to improve the distribution network at lowest cost) [24]. However, catering for variable generation capacity penetration on the transmission network is a fundamentally different issue to aggregated small-scale systems on distributed networks. While additional generations with a high capacity to resist power quality disturbances (which include synchronous generators, doubly-fed induction wind turbines, and also PV systems) are effective at providing ancillary services in high impedance networks [25], they distort the return on investment of technologies with a primary function of providing power quality services [26]. Therefore, the simple approach of dividing the value of real power (in $\mathrm{kW}$ ) from the value of reactive power (kVAr) and other characteristics of power quality can provide a mechanism to develop policies to incentivise new investments that more effectively contribute to power quality [25].

The evolution towards more competitive electricity markets has provided a much needed injection of rethinking traditional electricity investments and a platform for a larger scope of creative solutions on the transmission network. For example, it is increasingly common for transmission networks to include new devices designed for reducing total real and reactive power loss to reduce generation costs in deregulated markets [26-28]. For example, "Flexible AC Transmission System" (FACTS) technologies incorporate power electronics that enhance transmission system controllability and increase power transfer capacity by dynamically controlling transmission voltage, line impedance, and phase angle to fully utilise thermal limits of transmission lines, in addition to real and reactive power control $[26,27]$. While the additional costs borne by the transmission network operator will require relatively simple financial compensatory methods [3], the use of such technology on the distribution network will be less cost-effective due to lower economies of scale and necessitate new market arrangements for small-scale of distributed generation capacity with the ability to prove dynamic power control on the distribution network. At this time the economic costs and benefits from distributed technologies are generally captured by the network operator [5], but the present lack of market-based policy creativity led to the costs largely passed onto taxpayers rather than electricity consumers through cross-subsidies when network operators are government owned/controlled entities. Furthermore, network utilities do not have access to wide geographical measurements of power quality received at the level of the residential home, although with the development and implementation of advanced metering infrastructure (AMI) this will change [1]. Post-AMI introduction will generate large volumes of data regarding power characteristics at the distribution-level data at increasingly smaller increments of time, which will only increase the pressure on utilities and governments to improve the quality of electricity services $[1,8]$. Yet AMI and distributed automation technologies will also require improvements in distribution network power quality [29], as in contrast to relative to conventional network and metering components, the digital circuitry in some solid state electricity meters is relatively sensitive to power quality variations in a similar manner to many new domestic appliances [30].

\section{Options for PV Ramp Rates and Improving the Distribution Network}

4.1. Viewing Storage as Both "Power" and "Energy" Capacity. The utility of power electronically enabled power quality and storage devices includes the ability to decouple "power" and "energy" elements in the aim of providing additional flexibility and reliability of burst power and stable output while maintaining system integrity and quality of service $[31,32]$. However, the large "power" (in terms of kW) supply required to deliver a relatively small amount of energy (in terms of $\mathrm{kWh}$ ) is a challenge for conventional energy storage technologies. Traditional electrochemical battery systems are expensive and extremely limited by their depth of discharge and expire after a relatively low numbers of charge/discharge cycles $[33,34]$. Mitigating large and rapid PV ramp rates is unsuitable for conventional batteries due to high cycling and high efficiency requirements [22]. More modern energy and power capacity technologies give the ability for high penetration $\mathrm{PV}$ systems to provide power balancing and an ability to ride through transients to reliably power a distribution network, microgrid, or a stand-alone power system and avoid dumping any of the valuable PV generation output [33]. In contrast to conventional batteries, an example is the addition of supercapacitors to provide the needed large amplitude and frequency variations that batteries or other mitigation technologies are unable to effectively provide by themselves; supercapacitors can be utilised as a power source for both rapid cycling and rapid storage [9, 35]. The excellent temporal match between rapid PV ramp rates and supercapacitor capacity enables the provision of stable electricity outputs suitable for conventional load following generation and loads $[10,14,36-39]$. This is the basis behind 
the PNM system in New Mexico. The electrical charge of supercapacitors is stored in the double layer when an external voltage is applied [32] and exhibits charge times between 1 and 10 seconds, with a very low specific energy $\left(\mathrm{Wh} \mathrm{kg}^{-1}\right)$ and a high specific power $\left(\mathrm{W} \mathrm{kg}^{-1}\right)$, albeit at a higher cost $\left(\sim \mathrm{USD} \$ 20 \mathrm{Wh}^{-1}\right)$ [35]. At present supercapacitor technology requires reductions in capital cost to become competitive with battery systems on grid-connected applications [40], although this is rapidly being achieved, and optimised smaller supercapacitor banks have the technical capacity to manage short-term rapid power flows outside of nominal ratings as a compromise to minimise costs [10]. The numerous advantages of supercapacitors include their relatively small size, high energy density, nonelectrochemical-based components, high discharge/charge current tolerance, low maintenance requirements, high longevity, zero aging effects, and zero irreversible chemical reaction deratings $[32,36]$. The ability for high frequency supercapacitor switching increases electricity system architecture efficiency, particularly under conditions of high irradiance volatility [41].

4.2. PV Inverter System Capacity. The additional (commonly unutilised) capability of PV systems to autonomously provide reactive power to support network voltage recovery from faults is another missed opportunity. Multiple voltage control concepts have been proposed, including Dynamic Reactive Current Support functions [42]. One incarnation of this function colloquially known as "Var priority" (as opposed to "Watt priority") is a deviation from traditional MPP tracking that decreases real power during subsecond short-term low voltage conditions and gives some idea of how inverters are able to respond to the challenges of both PV ramping and distribution network power quality challenges [14]. While the existing conventional capacitors and inductors used in inverters consequently attenuate some of the shortterm system variability of PV ramping, the introduction of supercapacitor banks now gives an additional technical ability to maintain stable voltages and currents along a distribution feeder by either being switched off or absorbing electricity during high PV output intervals, complementing the ability for PV inverters to absorb or produce reactive and active power to maintain network stability. These new options enable the expansion of microgrid which cluster loads and generators to operate as a single controllable islanded system or within a main grid [33]. At present microgrids are often overloaded causing localised blackouts, and both power and energy demand limiting are generally required [43]. The addition of distributed PV systems with new inverter and ramp rate attenuation technologies can load balance, dynamically control power flows, and improve system restarts after fault with LVRT capability. However, such a large diversity of advancing technical abilities of power electronics means little if policy-makers and network operators do not explore new means to distribute the costs and benefits within electricity markets effectively and fairly. The lack of parallel advancements in electricity policy and pricing mechanisms alongside the technological advancements are preventing appropriate incentives to invest in appropriate solutions that improve dynamic power quality and maximise the capacity of networks to meet the growing diversity of new loads and generation within regulated standards of power quality.

4.3. Forecasting. PV systems can exhibit extremely fast "ramp-up" and "ramp-down" characteristics relative to all other conventional generators due to rapid changes in incident solar irradiance on the array generating close to rated output to near-zero in time intervals of one second under highly variable meteorological conditions [10-12, 18]. The ability to plan ahead at least one day to provide firm dispatchable power is deemed essential in many electricity network operation decision-making [18], and high resolution PV system data is urgently needed for improved generator output forecasting to assist scheduling to manage some intermittency [8]. The availability of higher precision meteorological forecasts specifically for PV system procurement can also be complemented by on-site irradiance monitoring to assist subsecond/minute automated network management systems. Instead of photodetector sensors common in meteorological data systems, a pilot PV cell is also effective means of obtaining instantaneous data when calibrated to a larger PV array comprised of identical materials, negating signal conditioning methods to obtain information useful to maximum power point trackers (MPPTs) and network operators [32]. Combining both improved PV-specific meteorological predictions and sensing with pilot PV cells can lead to projections of likely PV performance seconds ahead of time to enhance overall efficiency of meeting a load or a compensatory storage device. However, a greater availability of high resolution (1-second resolution) solar irradiance and PV system data (like the PNM data above) is urgently needed for improved generator output forecasting to assist scheduling to manage some intermittency [8].

4.4. Inverter Maximum Power Point Tracking. By curtailing the PV output via operating the converters/inverters off the MPP, PV ramp rates can be limited $[11,12]$. In the case of upward ramp rates, the inverter can simply curtail the PV power when reaching the ramp rate limit. In the case of downward ramp rates, however, the inverter must preemptively reduce the output power so that when the forecast cloud reaches the array, the ramp magnitude is reduced. This could be executed with MPPT which incorporates a referenced pilot PV cell. The fast dynamic response times of using the maximum power point (MPP) of a pilot PV cell or a parallelconfigured/decentralised PV inverter algorithm developed by Patel and Agarwal [44] can be effective means of using MPPT to maximise system output while reducing $\mathrm{PV}$ ramp rates under complex and rapidly changing lighting conditions.

It is known that larger spatial PV footprints average the smaller location-specific interval irradiance variability and associated PV ramp rates [12]. An alternative, yet related approach is to scale-down PV array strings by utilizing high efficiency, lower power MPPT systems with smaller distributed inverters to assist with highly variable meteorological conditions [32]. Rapid fluctuations in PV shading patterns make MPP tracking difficult with each system string 
MPP value dependent on upstream PV module characteristics. In cases of shaded PV systems with bypass diodes, the power-voltage curve contains multiple local maxima which perturb and observe (P\&O) MPPT algorithms have difficulty handling $[20,33]$.

\section{Conclusion}

There is an opportunity for energy policy to enable new technologies to improve distribution network power quality by establishing cost-recovery mechanisms in bilateral electricity markets, short-term markets, load balancing markets, and capacity markets by properly valuing the procurement of frequency and voltage control services. However, at present electricity markets generally favour conventional spinning reserve options or DSM rather than automated technologies that are suitable for rapid response on the distribution network and smaller lines in the transmission network. Crucially, distribution networks have largely been ignored in terms of investment, yet they are commonly a growing cost component in the total network and associated electricity price increases; in some jurisdictions the distribution network is expected to be an increasingly large cost component that outstrips the larger transmission networks. However, decision-makers largely do not have the data to assess power quality characteristics at the level of the residential home or large sections of the distribution network. Yet with AMI implementation the increasingly available distribution network data will bring sharp attention and additional pressure to the likelihood of major portions of the network at times not meeting the standards they are required to meet $[1$, 8]. While network operators may have access to increasing data and technology to control distributed generation for power quality improvements [8], they may not have the certainty of a cost-recovery mechanism to incentivise the needed investments and pass these costs and benefits to the market participants who may be able to most effectively provide the technical enhancements. For example, at present the economic costs and benefits from distributed technology voltage and frequency control ancillary services are generally captured by the network operator [5]. On public networks, costs and benefits are commonly passed onto taxpayers rather than electricity consumers through broad historical crosssubsidies. At this time, even regulated competitive electricity markets often allow the costs of associated network upgrades to be source from the government with limited regard to the economic efficiency of the total investment required [2]. Nonetheless, it is clear that new clean energy systems and support infrastructure on the distribution network have the capability to decrease network emission factors, improve frequency and voltage control, and improve network infrastructure and many other technical benefits [3]. Conversely, while there are technical limitations and variability issues associated with many decentralised renewable energy systems, there are several electricity market advantages including short capacity construction times, reduced transmission and distribution power losses, a deferral of traditional transmission and distribution upgrades, fuel supply diversity and associated security, and improvements in power quality [2, $7,45]$. Unfortunately, due to policy failures many of these benefits and costs remain outside market transactions and are either positive or negative externalities that are increasingly leading suboptimal electricity network outcomes.

\section{Competing Interests}

All authors declare no competing interests in relation to this paper.

\section{Acknowledgments}

Sandia National Laboratories is a multiprogram laboratory managed and operated by Sandia Corporation, a wholly owned subsidiary of Lockheed Martin Corporation, for the US Department of Energy's National Nuclear Security Administration under Contract DE-AC04-94AL85000. This project was also generously funded by the AustralianAmerican Fulbright Commission.

\section{References}

[1] M. P. McHenry, "Technical and governance considerations for advanced metering infrastructure/smart meters: technology, security, uncertainty, costs, benefits, and risks," Energy Policy, vol. 59, pp. 834-842, 2013.

[2] M. P. McHenry, "Policy options when giving negative externalities market value: clean energy policymaking and restructuring the Western Australian energy sector," Energy Policy, vol. 37, no. 4, pp. 1423-1431, 2009.

[3] M. P. McHenry, M. Schultz, and K. O’Mara, "Wholesale electricity markets and electricity networks: balancing supply reliability, technical governance, and market trading in the context of Western Australian energy disaggregation and marketisation," in Advances in Energy Research, Volume 5, A. R. McAdams, Ed., Nova Science Publishers, Hauppauge, NY, USA, 2011.

[4] M. P. McHenry, "Are small-scale grid-connected photovoltaic systems a cost-effective policy for lowering electricity bills and reducing carbon emissions? A technical, economic, and carbon emission analysis," Energy Policy, vol. 45, pp. 64-72, 2012.

[5] M. P. McHenry, "Small-scale ( $\leq 6 \mathrm{kWe}$ ) stand-alone and gridconnected photovoltaic, wind, hydroelectric, biodiesel, and wood gasification system's simulated technical, economic, and mitigation analyses for rural regions in Western Australia," Renewable Energy, vol. 38, no. 1, pp. 195-205, 2012.

[6] S. Reichelstein and M. Yorston, "The prospects for cost competitive solar PV power," Energy Policy, vol. 55, pp. 117-127, 2013.

[7] M. Monjas-Barroso and J. Balibrea-Iniesta, "Valuation of projects for power generation with renewable energy: a comparative study based on real regulatory options," Energy Policy, vol. 55, pp. 335-352, 2013.

[8] S. Sayeef, S. Heslop, D. Cornforth et al., Solar Intermittency: Australia's Clean Energy Challenge: Characterising the Effect of High Penetration Solar Intermittency on Australian Electricity Networks, CSIRO, Australian Solar Institute, Canberra, Australia, 2012.

[9] V. Lazarov, Z. Zarkov, H. Kanchev, L. Stoyanov, and B. Francois, "Compensation of power fluctuations in PV systems with supercapacitors," Elektrotechnica \& Elektronica, vol. 47, pp. 48$55,2012$. 
[10] N. Kakimoto, H. Satoh, S. Takayama, and K. Nakamura, "Ramprate control of photovoltaic generator with electric double-layer capacitor," IEEE Transactions on Energy Conversion, vol. 24, no. 2, pp. 465-473, 2009.

[11] J. Johnson, B. Schenkman, A. Ellis et al., Initial Operating Experience of the 1.2-MW La Ola Photovoltaic System, Sandia National Laboratories, Albuquerque, NM, USA, 2011.

[12] J. Johnson, B. Schenkman, A. Ellis, J. Quiroz, and C. Lenox, "Initial operating experience of the 1.2-MW La Ola photovoltaic system," in Proceedings of the IEEE 38th Photovoltaic Specialists Conference (PVSC '12), pp. 1-6, IEEE, Austin, Tex, USA, June 2012.

[13] X. Zeng, K. K. Li, W. L. Chan, and X. Yin, "Some novel techniques for improving power quality in distribution networks," in Proceedings of the IEEE International Conference on Electric Utility Deregulation, Restructuring and Power Technologies (DRPT 0’4), pp. 306-310, Hong Kong, April 2004.

[14] H. Tian, F. Gao, and C. Ma, "Novel low voltage ride through strategy of single-stage grid-tied photovoltaic inverter with supercapacitor coupled," in Proceedings of the IEEE 7th International Power Electronics and Motion Control Conference (IPEMC '12), pp. 1188-1192, Harbin, China, June 2012.

[15] F. A. Vaiwan, Voltage Control and Voltage Stability of Power Distribution Systems in the Presence of Distributed Generation, Chalmers University of Technology, Göteborg, Sweden, 2008.

[16] International Electrotechnical Commission (IEC), Communication Networks and Systems for Power Utility Automation-Part 90-7: Object Models for Power Converters in Distributed Energy Resources (DER) Systems, IEC, Geneva, Switzerland, 2013.

[17] D. Roberson, J. F. Ellison, D. Bhatnagar et al., Performance Assessment of the PNM Prosperity Electricity Storage Project. A Study for the DOE Energy Storage Systems Program, Sandia National Laboratories, Livermore, Calif, USA, 2014.

[18] S. Willard, B. Arellano, J. Hawkins et al., A Case Study on the Demonstration of Storage for Simultaneous Voltage Smoothing and Peak Shifting, The Electric Power Research Institute, Palo Alto, Calif, USA, 2012.

[19] M. P. McHenry, "A technical, economic, and greenhouse gas emission analysis of a homestead-scale grid-connected and stand-alone photovoltaic and diesel systems, against electricity network extension," Renewable Energy, vol. 38, no. 1, pp. 126$135,2012$.

[20] L. Gao, R. A. Dougal, S. Liu, and A. P. Iotova, "Parallelconnected solar PV system to address partial and rapidly fluctuating shadow conditions," IEEE Transactions on Industrial Electronics, vol. 56, no. 5, pp. 1548-1556, 2009.

[21] W. M. Rohouma, I. M. Molokhia, and A. H. Esuri, "Comparative study of different PV modules configuration reliability," Desalination, vol. 209, no. 1-3, pp. 122-128, 2007.

[22] H.-R. Seo, G.-H. Kim, S.-Y. Kim et al., "Power quality control strategy for grid-connected renewable energy sources using PV array and supercapacitor," in Proceedings of the International Conference on Electrical Machines and Systems (ICEMS '10), pp. 437-441, IEEE, Incheon, South Korea, October 2010.

[23] Independent Market Operator Western Australia, 2008 Statement of Opportunities Report, Independent Market Operator, Perth, Australia, 2008.

[24] Independent Market Operator (IMO), Statement of Opportunities, Independent Market Operator (IMO), Perth, Australia, 2009.
[25] A. Morton, S. Cowdroy, and D. Stevens, "Maximising the penetration of intermittent generation in the SWIS," Econnect Project 1465, Econnect, Melbourne, Australia, 2005.

[26] A. Kazemi and H. Andami, "FACTS devices in deregulated electric power systems: a review," in Proceedings of the IEEE International Conference on Electric Utility Deregulation, Restructuring and Power Technologies (DRPT '04), vol. 1, pp. 337-342, Hong Kong, April 2004.

[27] X.-P. Zhang, C. Rehtanz, and B. Pal, Flexible AC Transmission Systems: Modelling and Control, Springer, Berlin, Germany, 2006.

[28] S. C. Srivastava and R. K. Verma, "Impact of FACTS devices on transmission pricing in a de-regulated electricity market," in Proceedings of the International Conference on Electric Utility Deregulation and Restructuring and Power Technologies (DRPT '00), pp. 642-648, London, UK, April 2000.

[29] Victorian Auditor General, Towards a 'Smart Grid'-The RollOut of Advanced Metering Infrastructure, Victorian AuditorGeneral's Office, Melbourne, Australia, 2009.

[30] Electric Power Research Institute (EPRI), Accuracy of Digital Electricity Meters, Electric Power Research Institute (EPRI), Palo Alto, Calif, USA, 2010.

[31] J. M. Miller and G. Sartorelli, "Battery and ultracapacitor combinations-where should the converter go?" in Proceedings of the IEEE Vehicle Power and Propulsion Conference (VPPC '10), pp. 1-7, IEEE, Lille, France, September 2010.

[32] D. Brunelli, C. Moser, L. Thiele, and L. Benini, "Design of a solar-harvesting circuit for batteryless embedded systems," IEEE Transactions on Circuits and Systems I: Regular Papers, vol. 56, no. 11, pp. 2519-2528, 2009.

[33] S. Manfredi and M. Pagano, "On the use of ultracapacitor to support microgrid photovoltaic power system," in Proceedings of the 3rd International Conference on Clean Electrical Power: Renewable Energy Resources Impact (ICCEP '11), pp. 491-497, Ischia, Italy, June 2011.

[34] T. Robbins and J. M. Hawkins, "Powering telecommunications network interfaces using photovoltaic cells and supercapacitors," in Proceedings of the 19th International Telecommunications Energy Conference (INTELEC '97), pp. 523-528, IEEE, Melbourne, Australia, October 1997.

[35] M. Das, I. Das, N. K. Bhattacharyya, D. Mukherjee, and H. Saha, "Application of supercapacitor to power small electronic appliances," IOSR Journal of Electrical and Electronics Engineering, vol. 4, no. 3, pp. 28-32, 2013.

[36] N. Li, J. Zhang, and Y. Zhong, "A novel charging control scheme for super capacitor energy storage in photovoltaic generation system," in Proceedings of the 3rd International Conference on Electric Utility Deregulation and Restructuring and Power Technologies (DRPT'08), pp. 2671-2675, IEEE, Nanjuing, China, April 2008.

[37] Y. Zhong, J. Zhang, G. Li, and X. Yuan, "Mathematical model of new bi-directional DC-AC-DC converter for supercapacitor energy storage system in photovoltaic generation," in Proceedings of the 3rd International Conference on Deregulation and Restructuring and Power Technologies (DRPT '08), pp. 26862690, Nanjuing, China, April 2008.

[38] W. Marańda and M. Piotrowicz, "Short-time energy buffering for photovoltaic system," in Proceedings of the 17th International Conference Mixed Design of Integrated Circuits and Systems (MIXDES '10), pp. 525-528, Wrocław, Poland, June 2010.

[39] A. Fahad, T. Soyata, T. Wang, G. Sharma, W. Heinzelman, and K. Shen, "SOLARCAP: super capacitor buffering of solar energy 
for self-sustainable field systems," in Proceedings of the IEEE International SOC Conference (SOCC '12), pp. 236-241, IEEE, Niagara Falls, NY, USA, September 2012.

[40] A. K. Srivastava, A. A. Kumar, and N. N. Schulz, "Impact of distributed generations with energy storage devices on the electric grid," IEEE Systems Journal, vol. 6, no. 1, pp. 110-117, 2012.

[41] D. Dondi, A. Bertacchini, L. Larcher, P. Pavan, D. Brunelli, and L. Benini, "A solar energy harvesting circuit for low power applications," in Proceedings of the IEEE International Conference on Sustainable Energy Technologies (ICSET '08), pp. 945-949, Singapore, November 2008.

[42] Electric Power Research Institute (EPRI), Common Functions for Smart Inverters, Version 3, Electric Power Research Institute (EPRI), Palo Alto, Calif, USA, 2014.

[43] M. Vandenbergh, S. Beverungen, B. Buchholz et al., "Expandable hybrid systems for multi-user mini-grids," in Proceedings of the 17th European Photovoltaic Solar Energy Conference (EPVSEC '01), Munich, Germany, 2001.

[44] H. Patel and V. Agarwal, "Maximum power point tracking scheme for PV systems operating under partially shaded conditions," IEEE Transactions on Industrial Electronics, vol. 55, no. 4, pp. 1689-1698, 2008.

[45] R. E. H. Sims, R. N. Schock, A. Adegbululgbe et al., Energy Supply, Cambridge University Press, Cambridge, UK, 2007. 

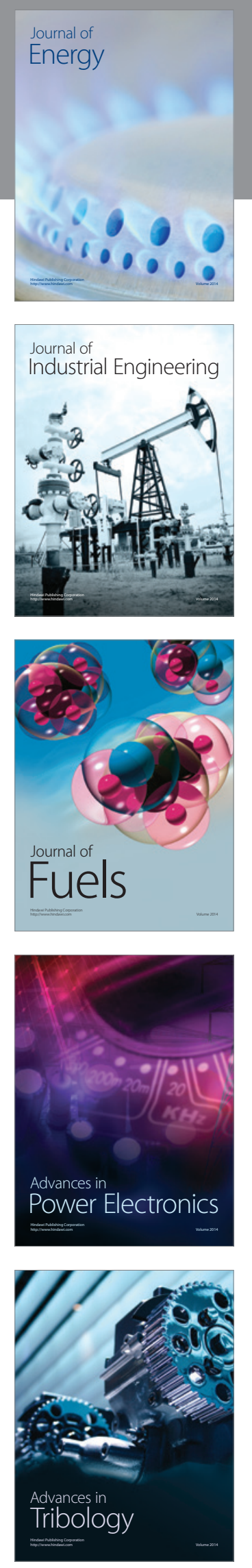
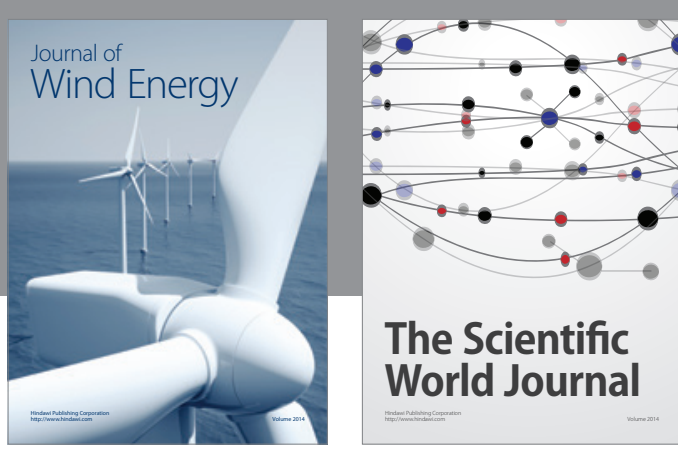

The Scientific World Journal
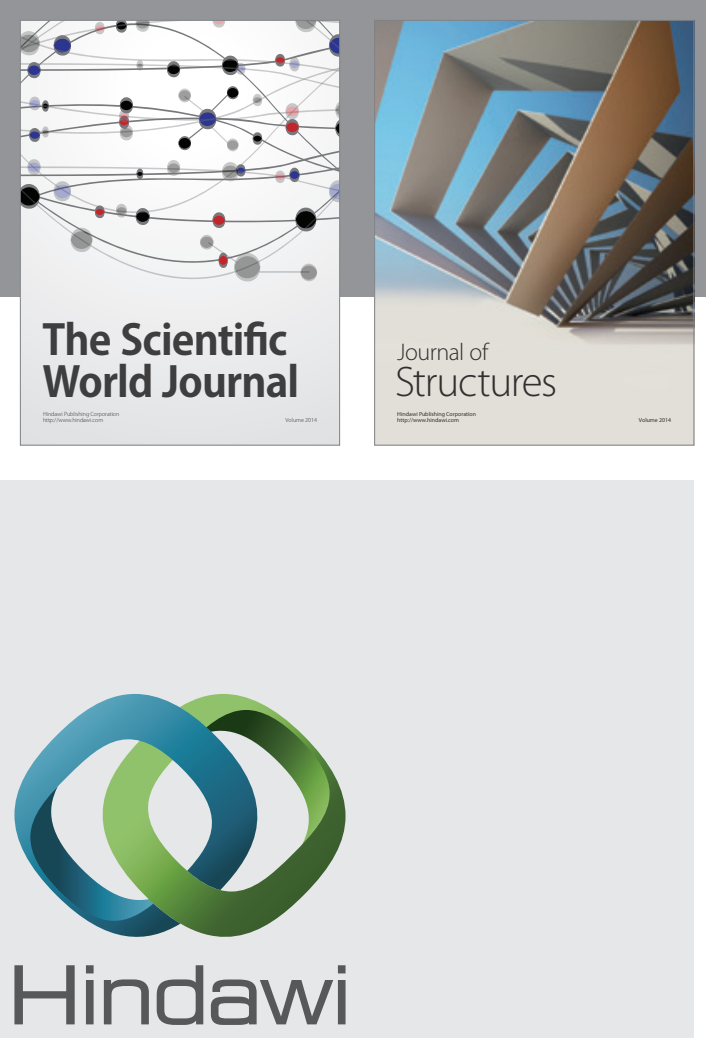

Submit your manuscripts at

http://www.hindawi.com
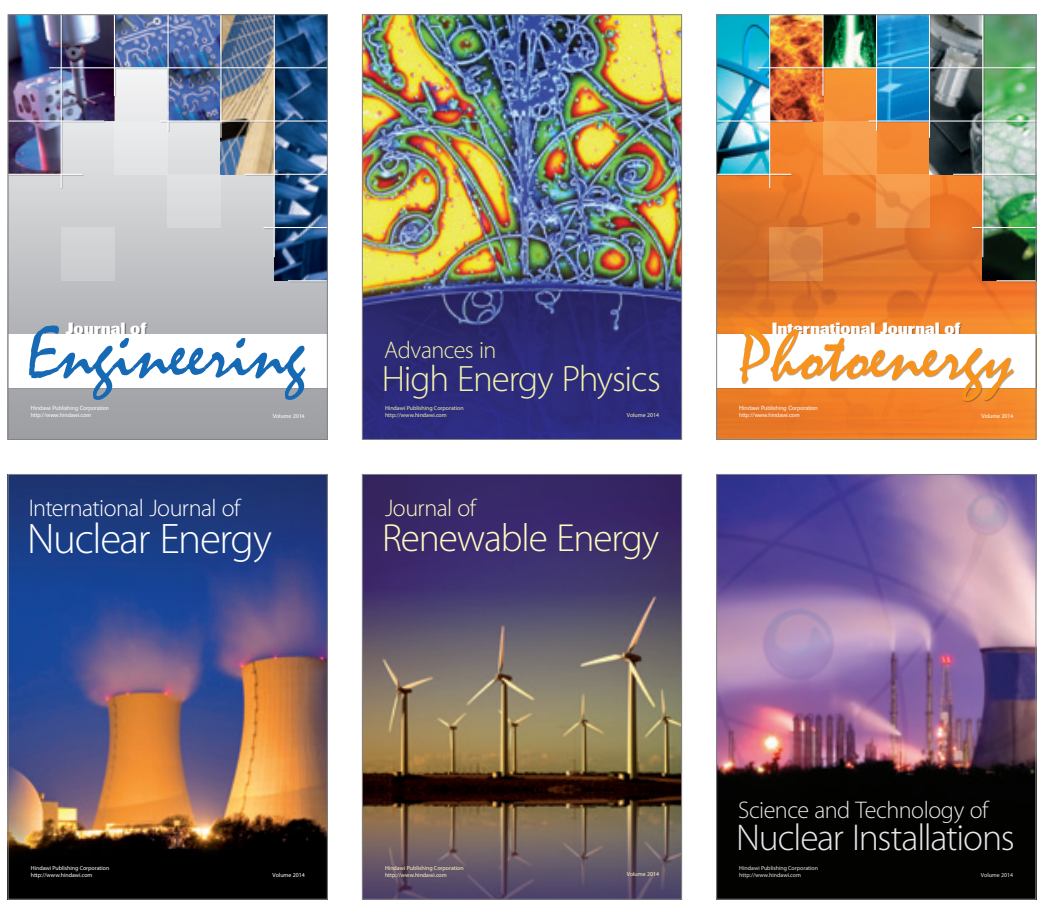
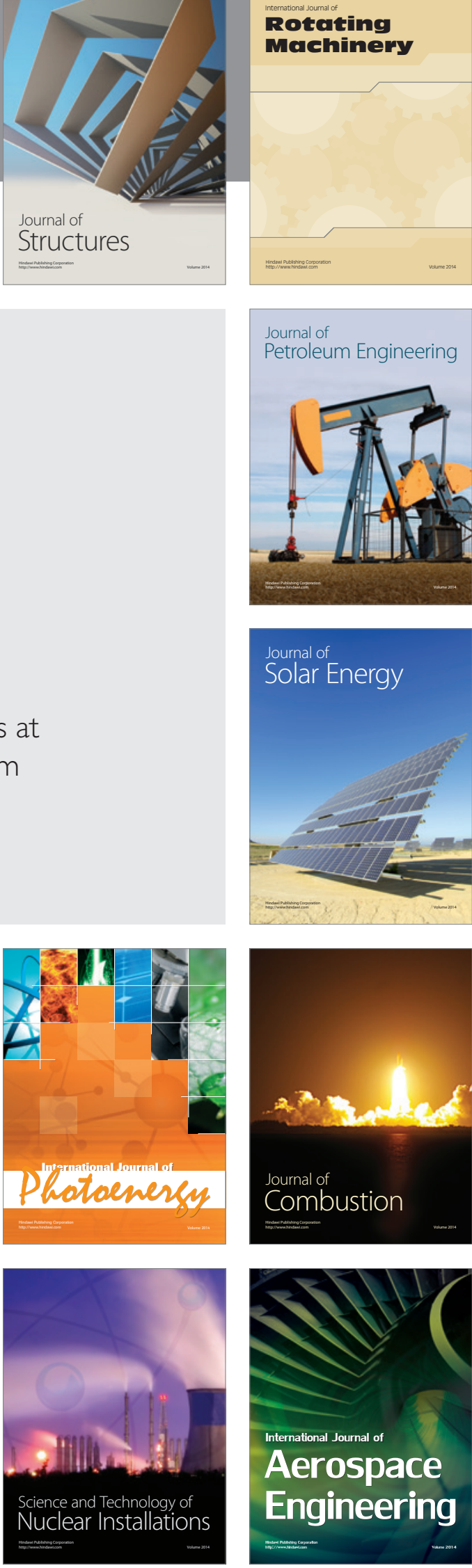